\title{
O SISTEMA CIBERNÉTICO DO MECANISMO DO PARTO EM APRESENTAÇÃO DE VÉRTICE - INTERPRETAÇÃO DIDÁTICO-PEDAGÓGICA
}

\author{
Efigenia Britez Fariña* \\ Toribia Mottos* \\ Maria Esperança de Marchiori Pedroso* \\ Doroty Leite Barbieri*
}

BRITEZ FARIÑA, E.; MOTTOS, T.; PEDROSO, M. E. de M.; BARBIERI, D. L. O sistema cibernético do mecanismo do parto em apresentação de vértice - interpretação didático-pedagógica. Rev. Esc. Enf. USP, São Paulo, 14(2):171-177, 1980.

Os autores, neste trabalho, de caráter didático-pedagógico, destinado a alunas do curso de obstetrícia, consideram especialmente o fenômeno do mecanismo de parto do ponto de vista de sua interpretação axiomática.

\section{INTRODUÇÃO}

Entende-se por sistema cibernético do mecanismo do parto, o conjunto de movimentos que realiza o móvel, ou seja, o feto, em seu trânsito pelo trajeto pelvi-genital, que se estende da cavidade uterina até o exterior.

Neste trabalho nos propomos a interpretar os movimentos realizados pelo polo cefálico durante o trabalho de parto, nas apresentações cefálicas fletidas. Procuraremos abordar o assunto de maneira simples e sucinta, para melhor compreensão do estudante de enfermagem. Evitaremos repetir conhecimentos semiológicos que são encontrados na literatura especifica.

A cibernética do parto tem características bem definidas em cada uma das apresentaçōes. Devido à complexidade e extensão do assunto, nos limitaremos a analisar a mecânica do parto em apresentação de vértice, pois essas ocorrem em 95,5\% dos casos. Nesta modalidade os partos se processam comumente em condições ideais e oferecem melhor prognóstico clínico e mecânico. É o que apresenta maior probabilidade de término feliz, no qual todos os fatores que intervêm no grande processo contribuem para a realização, de modo mais fácil, do trabalho da mãe e "trabalho do feto", com menor desgaste, traumatismo e sofrimento; numa palavra, de maneira mais leve.

Não consideraremos aqui o mecanismo de desprendimento do ovóide córmico, pois não é finalidade deste trabalho entrar em detalhe minucioso do mecanismo em si; pretendemos, unicamente, encarar seus princípios gerais.

\footnotetext{
* Professor Assistente das disciplinas Enfermagem Obstétrica e Neonatal e Enfermagem Ginecológica da EEUSP.

* * Auxiliar de Ensino das disciplinas Enfermagem Obstétrica e Neonatal e Enfermagem Ginecológica da EEUSP.
} 


\section{NOÇÕES FUNDAMENTAIS PARA A INTERPRETAÇÃO DO MECANISMO DE PARTO}

O sistema do mecanismo de parto será analisado por uma interpretação puramente cinética, donde podemos afirmar que ele é resultante de um movimento fundamental, cardinal, continuado, com uma série de movimentos secundários ou complementares.

O movimento fundamental a ser interpretado é a progressão do feto sob o impulso da dinâmica útero-abdominal; os movimentos complementares são traduzidos por rotações.

A flexão cefálica é o movimento cardinal no mecnaismo de parto, porque resulta nas diminuições lineares dos diâmetros da cabeça fetal, para que possa progredir através do canal pelvi-genital.

O assinclitismo da insinuação é uma rotação sobre o eixo vertical cefálico e os movimentos restantes são renovadas rotações sobre um eixo vertical.

Assim considerado o mecanismo de parto, surge de imediato a pergunta: por que razão o móvel fetal tem que executar, antes de nascer, essa sucessão de movimentos verdadeiramente admiráveis, de grande regularidade e exatidão?

O esclarecimnto deste problema tem dado origem a vasta literatura e a famosas controvérsias. Profissionais e estudantes responsáveis pela condução do parto não devem ignorar os fenômenos íntimos da mecânica obstétrica. $O$ problema central não é só saber como se processa tal ou qual movimento, mas também porque.

Apesar das inúmeras teorias, existem na mecânica obstétrica muitos pontos ainda não elucidados; entretanto há uma gama de conhecimentos científicos baseados em fatos concretos e incontrovertíveis que, reunidos, dão margem a uma doutrina de base sólida.

Para a correta interpretação do sistema cibernético do mecanismo do parto, é necessário que o aluno grave inicialmente as três noções principais de: espaço, forças e movimento. Em termos mais precisos: noção estereométrica, noção estereodinâmica e noção de continuidade dinâmica.

A noção estereométrica é a condição prévia a toda observação topográfica feto-materna.

Ao tomar um livro para estudar o mecanismo do parto e ao contemplar as figuras que o ilustram, todos os processos que o constituem e todos os tempos em que este se decompõe ocorrem num único plano real: o plano das folhas que estamos lendo; o resto é virtual e imaginativo. Uma coisa é a noção planimétrica do livro, do quadro-negro, da projeção; outra, diferente, é a noção do espaço corporal.

Os movimentos fetais se processam, não em uma superfície, mas através de numerosas superfícies. Tanto o feto como o trajeto são volumes. É precisamente essa diferença geométrica entre o parto autêntico de uma mulher real e a 
imagem planimétrica que o aluno muitas vezes não consegue compreender em toda a sua magnitude.

Para interpretar o mecanismo do parto, portanto, o aluno deve habituar-se a pensar estereometricamente e não planimetricamente.

A noção estereodinâmica procura incutir no aluno, desde o início, a idéia de que a mecânica do parto deve ser considerada sob o aspecto das forças que entram em jogo, com a finalidadı do móvel ser intpulsionado através do trajeto. Isto nada mais é que uma associação de energias, com a finalidade de produzir um trabalho. As contrações uterinas e os esforços expulsivos são a fonte de produção desta energia vital, que irá resultar em dois fenômenos básicos do trabalho de parto: a dilatação cervical e a propulsão do feto, ou seja, o próprio fator mecânico do parto.

O motor útero-abdominal materno nada mais é que a máquina natural, ou seja, o agente primário que põe em movimento o móvel em sua progressão ao longo do trajeto. Mas esta força motriz, na sua luta com as resistências entre o continente e o conteúdo, dá origem a uma série de potências secundárias, de extraordinária importância para a evolução mecânica normal do trabalho.

A noção de continuidade dinâmica significa que o processo mecânico inicia, continua e termina em um único ato, sem interrupção. Os diferentes movimentos que executa o feto dividem-se didaticamente em certo número de fases ou tempos, mas tais movimentos nada mais são do que a combinação de um movimento fundamental, o da progressão, com outros movimentos acessórios que são denominados rotações. As resultantes destas combinações são paulatinas, contínuas, coordenadas e sem estacionamentos. A denominada rotação interna não é um movimento longitudinal, nem transversal, nem circular, e sim um movimento helicoidal.

Ao citar a continuidade cinética, é óbvio, nos referimos ao parto fisiológico Claro está que se ocorrer, por qualquer causa, a cessação da dinâmica uterina, estaremos fatalmente na presença de uma interrupção mecânica.

\section{FATORES ESSENCIAIS QUE INTERVEM NO PARTO}

Finalizadas as três premissas que nós conceituamos indispensáveis à boa compreensão da cibernética do parto, passaremos à interpretação dos diferentes movimentos executados pelo feto durante o seu trajeto no canal de parto.

Sendo assim é necessário citar três fatores essenciais que intervêm no mecanismo de parto: a força, o trajeto e o objeto.

\section{Força motriz}

A força motriz é constituída por contrações uterinas durante o trabalho de parto e por esforços expulsivos decorrentes de contrações do diafragma e dos músculos retos, oblíquos e transversos do abdômen. Essa somatória de forças tem por finalidade promover a dilatação cervical (ação tratora), a progressão da apresentação e a expulsão do feto (ação propulsora). 
0 trajeto é a passagem que o objeto (feto) vai percorrer impulsionado pelo motor (útero); estende-se do útero à fenda vulvar.

O trajeto apresenta-se sob a forma de um cilindro curvo, que se orienta de cima para baixo e de dentro para fora. Podemos considerar esse cilindro como se fosse constituído de duas partes: uma superior, formada pelo segmento inferior do útero e pelo colo, e a inferior, representada pela região períneo-vulvar; estas, por sua vez, constituem as partes moles do canal de parto. Devemos ressaltar que as duas porções citadas são interligadas pela pelve óssea, que é a mais importante parte do trajeto, por seu pronunciado grau de rigidez.

Como as partes rígidas do trajeto são revestidas por partes moles, formam-se irregularidades de calibre, de per si pequenas em relação ao tamanho do conduto, as quais se corrigem à medida que vai progredindo o feto. $\mathrm{O}$ trajeto, portanto, adquire uma luz circular, importante para a realização normal dos movimentos fetais em seu trânsito desde o útero até o extcrior.

Objeto

O objeto ou móvel é representado pelo feto que vai percorrer o trajeto impulsionado pela força motriz.

$\mathrm{Na}$ sua atitude normal de flexão dentro da cavidade uterina, o feto se assemelha a um ovóide. Este ovóide fetal se apresenta com dois segmentos bem determinados: ovóide cefálico e ovóide córmico; o primeiro reveste-se de importância maior devido a seu volume, maior consistência e sua menor redutividade. A elasticidade do feto é assimétrica. $O$ feto não é rígido, e sim semi-rígido; não é homogêneo, pois apresenta propriedades plásticas e elásticas.

\section{CIBERNÉTICA DO MECANISMO DO PARTO}

Se o trajeto fosse um cilindro rígido, reto e de luz uniforme, e por ele passasse uma esfera ou cilindro também rígido, este percorreria aquele sem executar mais que um movimento, o de progressão ou translação, sem nenhuma rotação. 0 canal de parto, se assemelha a um cilindro, porém, não é reto, nem rígido, nem de luz uniforme, em seus diferentes níveis, e o móvel fetal não é esférico, nem cilíndrico, nem rígido.

O trajeto é inicialmente reto, passando a curvo em sua porção terminal; suas paredes quando distendidas, tornam-se semi-rigidas e sua luz se faz aproximadamente circular.

$\mathrm{O}$ feto é semi-rígido e irregular, mas se transforma num cilindro de periferia aproximadamente circular, de massa homogênea e de diferentes flexibilidades. Para este corpo tão desigual poder passar por um conduto irregular, e transpor os obstáculos que se lhe apresentam, precisará acomodar-se do melhor modo possível. Esta acomodação é o resultado das diferentes flexões e rotações. 
A fim de que o aluno possa compreender o primeiro tempo do mecanismo de parto, ou seja, a insinuação, procuraremos interpretar os tempos necessários à sua ocorrência.

Referem os autores de literatura especifica sobre o mecanismo de parto, que a insinuação do pólo cefálico se processa por meio de flexão, de acavalgamento ósseo e fenômeno de assinclitimo ${ }^{1,2,3,4}$.

A flexão cefálica nada mais é que uma redução linear, para que possa ocorrer a substituição dos maiores diâmetros cefálicos pelos menores. Para explicar a flexão cefálica têm-se invocado diferentes teorias que na realidade não se contradizem; procuram explicar o mesmo fenômeno, sob pontos de vista diferentes.

As teorias de Lahs e Sellheim, citadas pelos autores BRIQUET ${ }^{2}$ e ADEODATO FILHO ${ }^{1}$, procuram explicar a flexão através da ação das pressões laterais que as porções altas do canal de parto exercem sobre o pólo cefálico. Os mesmos autores citam a teoria de Zweifel, segundo a qual a flexão decorre da pressão axial do feto. A flexão se faz pela ação de duas forças antagônicas: uma, a contração uterina, que se transmite através da coluna vertebral do feto, de cima para baixo, e outra, representada pela resistência das paredes pélvicas. A articulação da coluna cervical na base do crânio não é central, e sim mais para o lado do occipital, resultando daí uma alavanca de braços desiguais, sendo o menor braço o que corresponde ao lado do occipital e o maior, o que corresponde ao da fronte. Da ação dessas forças antagônicas resulta a subida do braço maior (fronte), o que explica a flexão cefálica.

O acavalgamento ósseo é uma redução volumétrica do pólo cefálico, que se processa por meio da locação dos frontais e do occipital sob os parietais, e da sobreposição da borda de um parietal sobre o outro. Este é um fenômeno de natureza plástica, que desaparece quando deixa de atuar a potência que o gerou.

Quanto ao assinclitismo, as teorias mais aceitas para explicar este fenômeno são as de Lahs e Sellheim. Lahs invoca a lei do plano inclinado e Sellheim procura explicá-lo através da dimidiação cefálica.

Para que a cabeça fetal ultrapasse a área do estreito superior, além dos fenômenos já descritos, é necessário que haja também uma inclinação lateral, de forma a que cada metade do crânio ultrapasse separadamente esse estreito. 0 professor Fernando Magalhães citava em suas aulas que este movimento é semelhante ao feito pelo indivíduo quando vai ultrapassar uma porta mais estreita que suas espáduas; ele passa primeiro um ombro e depois o outro, de forma assinclítica.

Após a análise da insinuação, passaremos a interpretar o segundo e o terceiro tempos do mecanismo de parto, que são: a descida ou progressão e a rotação cefálica interna.

O pólo cefálico, em sua translação da área do estreito superior para o inferior, não executa um simples movimento de descida, executa, simultaneamente, um movimento de rotação.

Existem diversas interpretações da rotação interna do pólo cefálico, o que tem sido motivo de muitas discussões. As mais aceitas são as teorias baseadas nas leis do plano inclinado e a de SELLHEIM ${ }^{4}$. 
O assoalho pélvico é côncavo para cima e para diante e, sendo distendido pela cabeça fetal tem acentuada a sua forma. A cabeça fetal, deslizando pelas partes laterais do assoalho pélvico (plano inclinado), roda para acomodar seus maiores diâmetros aos maiores da fenda vulvar.

Para melhor compreensão da teoria de SELLHEIM ${ }^{4}$, que considera o feto como um dos principais fatores da rotação, são necessários alguns esclarecimentos que exporemos adiante.

Como já foi mencionado, o feto, mecanicamente considerado, é um cilindro de flexibilidades desiguais.

A cilindrização do feto é resultante de uma luta entre as paredes elásticas do trajeto e as propriedades elásticas dos tecidos do móvel, impulsionado na sua progressão pela força motriz útero-abdominal.

Segundo SELLHEIM, a luta entre o continente e o conteúdo gera duas novas forças secundárias: a tendência à constrição das paredes do trajeto, que é distendido pelo móvel, e a tendência à expansão do corpo fetal, que é comprimido pelo trajeto.

O fator de flexibilidade desigual se explica por razóes anatômicas intrínsecas da estrutura fetal e por fatores já referidos, que intervêm quando o feto mecanicamente é transformado em cilindro. Nessa flexibilidade desigual do feto intervêm os ossos, os músculos, as articulações etc. A flexibilidade máxima, por exemplo, na região cervical origina-se na nuca e na região dorso-lombar no sentido lateral.

\footnotetext{
A teoria de SELLHEIM ${ }^{4}$ explica a rotação interna do pólo cefálico, como segue:

"Quando um cilindro de flexibilidade desigual (feto) tem que atravessar um cilindro oco e encurvado (canal do parto), este cilindro será forçado a girar sobre seu eixo longitudinal (rotação interna), até que a direção de sua maior flexibilidade (nuca, na apresentação de vértice), coincida com a direção da curvatura do trajeto (eixo do canal)".
}

A seguir, o autor considera, também, outros fatores que intervêm no fenômeno complexo da rotação interna, como a "tensão de atitude" e a "tensão de desvio". 0 primeiro é representado pela tensão elástica do feto, produzida por sua flexão cefálica, e o segundo pela energia que concentra o cilindro fetal, quando é obrigado a fletir-se na passagem pelo ângulo do trajeto.

Os fatores de flexibilidade desigual, encurvamento axial, tensão de atitude e tensão de desvio são os que determinam no canal de parto a rotação da cabeça e dos ombros.

Durante o desprendimento cefálico, ou seja, no quarto tempo do mecanismo de parto, devido à curvatura inferior do trajeto o pólo cefálico se desprenderá por um movimento de deflexão.

Segundo alguns autores o despreendimento realiza-se em decorrência da ação de duas forças que atuam em sentido convergente, uma representada pela contração uterina e outra pela contrapressão do períneo. Outro fator que intervem no movimento de deflexão é o grau de flexibilidade da coluna cervical. 
SELLHEIM ${ }^{4}$ considera que a deflexão é a conseqüência de um movimento produzido por uma potência acumulada na nuca fetal quando tem que se flexionar para insinuar. A deflexão vai-se realizando à medida que a carga potencial acumulada (tensão de atitude) se transforma em carga real.

No quinto tempo do mecanismo de parto, ou seja, na rotação externa, por voltar o occipício a sua origem primitiva, esquerda ou direita, este movimento é denominado de restituição.

Ao se desprender o pólo cefálico, as espáduas, que se encontram no assoalho pélvico, pelos mesmos motivos que determinaram a rotação interna da cabeça rodam, com a finalidade de colocar o bi-acromial no diâmetro ântero-posterior do estreito inferior. Simultaneamente, a cabeça já desprendida acompanha esse movimento, realizando a rotação externa do pólo cefálico.

E, com isto, está concluído o desprendimento do pólo cefálico do feto. Assim, cremos ter interpretado de maneira clara e sucinta os movimentos que o pólo cefálico executa em seu trajeto pelo canal pelvigenital.

BRITEZ FARIÑA, E.; MOTTOS, T.; PEDROSO, M. E. de M.; BARBIERI, D. L. The cibernetic sistem of mechanism of labour - pedagogical interpretation. Rev. Esc. Enf. USP, São Paulo, 14(2):171-177, 1980.

The authors, in this work destined to midwifery students, consider specially the phenomena of the mechanism of labour, from the point of view of its axiomatic interpretation.

\section{REFERENCIAS BIBLIOGRAFICAS}

1. ADEODATO FILHO, J. Mecanismo do parto. In: REZENDE, J. de Obstetricia. 3. ed. Rio de Janeiro, Guanabara Koogan, 1974. cap. 14, p. 274-83.

2. BRIQUET, R. Fenómenos mecánicos do parto. In: — Obstetrícla normal. São Paulo, São Paul, 1970. cap. 16, p. 295-310.

3. GREENHIL, J. P. \& FRIEDMAN, E. Mecanismos do parto. In: Janeiro, Interamericana, 1976. cap. 18, p. 232-40.

4. SELLheIM, H. Diegeburt des Manschen. Wiesbaden, Bergman, 1913. p. 159-64. 